\title{
ARTE VISUAL, ESPACIO Y PODER: MANEJO INCAICO DE LA ICONOGRAFÍA CERÁMICA EN DISTINTOS ASENTAMIENTOS DE LA FASE DIAGUITA INKA EN EL VALLE DE ILLAPEL
}

\author{
VISUAL ART, SPACE AND POWER: INKA CERAMIC ICONOGRAPHY FROM \\ SEVERAL DIAGUITA-INKA SETTLEMENTS IN ILLAPEL VALLEY
}

\author{
Paola González Carvajal*
}

\begin{abstract}
En este trabajo se discute la estructura de los diseños cerámicos Diaguita Inka así como la distribución de estos materiales en varios sitios del río Illapel (Norte Semiárido Chileno). Este análisis revela una clara diferencia entre sitios con relación a la presencia de iconografía cuzqueña. La distribución diferencial de los patrones decorativos Inkas versus Diaguitas aporta información acerca de procesos relacionados con la vida cotidiana, así como diferencias locales en las estrategias políticas del Imperio Inka. Estrategias políticas diferenciales también son discernidas a un nivel regional a través de la comparación de los materiales procedentes del valle de Illapel en relación a los del área Diaguita nuclear (valles de Elqui y Limarí). Adicionalmente a la introducción de elementos Inkas, se perciben cambios significativos en el rol jugado por el arte visual Diaguita durante este período.
\end{abstract}

Palabras claves: Cultura Diaguita, Cultura Inka, valle de Illapel, iconografía cerámica y arte, estrategias imperiales estatales.

In this paper, I discuss the structure of Diaguita-Inka ceramic design as well as the distribution of this material among several sites in the Illapel valley of north-central Chile. The analysis reveals a clear difference between sites with respect to the Cuzco materials. The differential distribution of Diaguita vs. Inka decorative patterns in this valley provides information about processes of daily life as well as local differences in the political strategies of the imperial Inka state. Different political strategies can also be discerned at the regional level through the comparison of the Illapel materials with those from the Diaguita nuclear area (Elqui and Limari river valleys). In addition to the introduction of Inka elements, significant changes in Diaguita visual art are also noted.

Key words: Diaguita, Inka, ceramic iconography and art, Illapel valley, imperial state strategies.

La presente investigación define y compara los patrones decorativos de la fase Diaguita Inka en distintos asentamientos habitacionales del valle de Illapel. Este estudio hizo visible una gran diferencia en el universo representacional del sitio Loma Los Brujos, en comparación a los restantes asentamientos Diaguita Inka del valle. En efecto, Loma Los Brujos es el único asentamiento analizado que posee estructuras asociadas y está localizado en un lugar estratégico del valle, resultando visible a gran distancia y puede además acceder visualmente a los asentamientos Diaguita Inka del curso inferior del río. Su arte visual se caracteriza por poseer formas cerámicas y una iconografía casi netamente cuzqueña. Los restantes asentamientos Diaguita Inka analizados (Sucesión Ramírez, Familia Carvajal, Cárcamo 6, Césped 1 y Césped 3) se caracterizan, en tanto, por un aumento sorprendente en la cantidad de patrones decorativos manejados, muchos de ellos inexistentes en el área en la fase preinca, no obstante, el origen de estos diseños es claramente Diaguita. Además, comparten entre sí un gran número de diseños. El análisis de su arte visual y contexto, así como su relación con el sitio Loma Los Brujos nos llevan a plantear la existencia en este valle de una estrategia inca de dominio, o manejo político de estas poblaciones, diversa de la desarrollada en las áreas nucleares (valles de Elqui y Limarí), revelando también la instauración en este valle de artesanos ceramistas bajo el régimen de mitimaes. De igual modo, la clara determinación de los patrones decorativos existentes en estos asentamientos nos acerca a la dimensión cotidiana de estas poblaciones, reconociéndose cierta apropiación espacial de algunos patrones, así como un replanteamiento de códigos estéticos Diaguita, generados durante la fase preincaica.

\footnotetext{
* Sociedad Chilena de Arqueología, Proyecto Fondecyt 1040154, Emilia Téllez 5277, Ñuñoa, Santiago. paoglez@ 123.cl
} 


\section{Patrones Decorativos del sitio Loma Los Brujos y su vinculación con el Arte Visual de otros Asentamientos de la Fase Diaguita Inka en el Valle de Illapel}

A continuación se describirán los resultados de nuestro análisis de los patrones decorativos del Sitio Loma Los Brujos, en cuanto a su decoración y formas. La metodología se basa en los análisis de estructura del diseño, sensu Washburn (1977, 1983) y Washburn y Crowe (1988). Para la determinación del origen de los diseños se consideró los trabajos de Fernández Baca (1971), Cornejo (1989) y González (1995). Estos resultados se asocian a lo conocido acerca de otros asentamientos Diaguita Incaicos en el valle de Illapel revelados por las investigaciones de los Proyectos Fondecyt 1950012 y 1980248, descritos en González (2004), cuyo número de fragmentos y frecuencia de representación sobre el total de los sitios Diaguita Inka del valle se resumen en la Tabla 1.

\section{La muestra y resultados del análisis de simetría}

Del total de fragmentos decorados recobrados en el sitio Loma Los Brujos, sólo 117 permitieron la determinación de las unidades mínimas del diseño y la estructura simétrica que determinaba su distribución. Dividimos estas estructuras decorativas atendiendo al origen de los diseños (Cuzqueños, Diaguitas o Mixtos Diaguita Inka). Los porcentajes se refieren al total de fragmentos decorados con patrón simétrico reconocible del sitio Loma Los Brujos.

\section{Patrones Cuzqueños}

Se logró identificar un total de 15 patrones decorativos de origen cuzqueño, que reunían a un total de 109 fragmentos decorados, un 93,16\% del total de la muestra. Los patrones decorativos cuzqueños y sus correspondientes frecuencias de representación son los siguientes (Figura 1):

1. Reticulado oblicuo: 63 fragmentos $(53,84 \%$ del Total $/ 57,8 \%$ de los diseños Cuzqueños). Este motivo fue descrito por Fernández Baca (1971), en la figura 553 de la mencionada publicación (ver Figura 1 a).

2. Ajedrezado: Cuatro fragmentos $(3,42 \%$ del Total $/ 3,66 \%$ de los diseños Cuzqueños). Consiste de cuadrados negros alternados con cua- drados blancos que presentan en su interior líneas negras paralelas horizontales y se desplazan horizontal y verticalmente siguiendo el principio de traslación. Un diseño similar fue descrito por Fernández Baca (1971) en la figura 95 y siguientes de la mencionada publicación (ver Figura 1 b)

3. Clepsidras en translación vertical separadas por líneas horizontales paralelas: Siete fragmentos (5,98\% del Total $/ 6,42 \%$ de los diseños Cuzqueños). Este diseño fue descrito por Fernández Baca (1971) en la figura 149 de su obra (ver Figura $1 \mathrm{c}$ ).

4. Linea negra paralela horizontal bajo el borde: Un fragmento $(0,85 \%$ del Total $/ 0,91 \%$ de los diseños Cuzqueños). Hemos observado esta decoración en platos playos y ornitomorfos de la colección del Museo Arqueológico de La Serena (González, 1995) (ver Figura 1 d).

5. Patrón zigzag cuzqueño: Un fragmento de aríbalo $(0,85 \%$ Total $/ 0,91 \%$ de los diseños Cuzqueños). Descrito por Fernández Baca en la figura 232 de la mencionada publicación (ver Figura $1 \mathrm{e}$ ).

6. Banda vertical negra sobre café con líneas negras paralelas oblicuas en su interior: Dos fragmentos $(1,71 \%$ del Total $/ 1,83 \%$ de los diseños Cuzqueños). Este diseño también fue registrado en el sitio de Huana, por Niemeyer (1972) (ver Figura 1 f).

7. Rombos en hilera: 16 fragmentos $(13,67 \%$ Total/14,68\% de los diseños Cuzqueños): Se distinguen las variantes: a) Reticulado Oblicuo: Siete; b) Blancos: Cinco; c)Negros: Cuatro. La unidad mínima es un rombo que se desplaza horizontal o verticalmente siguiendo el principio de translación. Este motivo fue descrito por Fernández Baca (1971) en las figuras 391 y 424 de la misma obra. (Figura $1 \mathrm{~g}$ ).

8. Rombos aislados: Dos fragmentos $(1,70 \%$ del Total/1,83\% de los diseños Cuzqueños). La variante que presenta apéndices verticales se asemeja a la forma de ciertos "ojos" de jarro pato propios de la Fase Diaguita III. (González 1995) (ver Figura 1 h).

9. Reticulado perpendicular: Un fragmento (0,85\% Total $/ 0,91 \%$ de los diseños Cuzqueños). Fernández Baca (1971) lo ilustra en la Figura 585 de su obra (ver Figura 1 i).

10. Triángulos negros invertidos en translación horizontal: Dos fragmentos (1,70\% del Total/ $1,83 \%$ de los diseños Cuzqueños). Este moti- 
vo fue descrito por Fernández Baca en la figura 277 de la obra mencionada (ver Figura 1 j).

11. "Helechos": Seis fragmentos $(5,12 \%$ Total/ 5,5 $\%$ de los diseños Cuzqueños). Este diseño fue descrito por Fernández Baca (1971) en la figura 146 de su publicación (ver Figura 1 k).

12. Bastones en translación horizontal: Un fragmento $(0,85 \%$ Total $/ 0,91 \%$ de los diseños Cuzqueños). Este motivo fue definido por Fernández Baca (1971) como "embrión de la quínoa" y fue descrito en la figura 1662 de la mencionada publicación (ver Figura 11 ).

13. Círculos concéntricos con apéndices verticales: Un fragmento $(0,85 \%$ del Total $/ 0,91 \%$ de los diseños Cuzqueños). Este motivo fue representado por Fernández Baca (1971) en la figura 666 de su obra (ver Figura $1 \mathrm{~m}$ ).

14. Rectas verticales paralelas en translación horizontal: Un fragmento $(0,85 \%$ del Total/ $0,91 \%$ de los diseños Cuzqueños). Este motivo fue descrito por Fernández Baca (1971) en la figura 94 de su obra (ver Figura 1 n).

15. Linea zigzag horizontal sobre banda reticulada oblicua: Un fragmento ( $0,85 \%$ del Total/ $0,91 \%$ de los diseños Cuzqueños). Este motivo fue descrito por Fernández Baca (1971) en la figura 254 de la referida publicación (ver Figura $1 \tilde{\text { n)}) . ~}$

\section{Patrones Diaguita}

Se reconocieron sólo tres patrones decorativos de origen Diaguita en el total de la muestra. Los cuales en conjunto alcanzan sólo a siete fragmentos, un 5,98\% del total de la muestra analizada (Figura 2):

1. Patrón zigzag C: Tres fragmentos $(2,56 \%$ del total). El patrón Zigzag fue definido por Cornejo (1989). La unidad mínima es una greca escalerada lateralmente que sufre una reflexión desplazada y se traslada como un todo en dirección horizontal, hasta completar la banda. (Ver Figura 2 a).

2. Patrón zigzag A: Un fragmento $(0,85 \%$ del total). El patrón Zigzag fue definido por Cornejo (1989). La unidad mínima es una greca escalerada lateralmente y también en su sector superior, la que sufre una reflexión desplazada y se traslada como un todo en dirección horizontal, hasta completar la banda. (Ver Figura $2 \mathrm{~b}$ ).
3. Cuarto estilo: Tres fragmentos $(2,56 \%$ del total). Hasta el momento no ha sido posible describir las unidades mínimas y la estructura simétrica del patrón Cuarto Estilo. (Ver Figura 2 c).

\section{Patrones Mixtos Inka-Diaguitas}

Hemos considerado en esta categoría a los patrones que pese a poseer unidades mínimas de origen Diaguita la estructura del diseño ha sufrido variaciones por efecto de la influencia incaica. Se identificó sólo un diseño de estas características (un $0,85 \%$ del total de diseños) (Figura 2).

1. Escalerado en reflexión vertical: Un fragmento. La unidad mínima es un diseño escalerado que sufre una reflexión vertical, cuyo segmento más ancho coincide con la base del ceramio y se angosta a medida que avanza al interior. (Ver Figura $2 \mathrm{~d}$ ).

\section{Formas cerámicas}

A partir del análisis de los fragmentos decorados hemos podido identificar varias formas típicas de la ergología Diaguita Inka, correspondiente a las siguientes formas cerámicas cuzqueñas (aríbalos, platos playos, platos ornitomorfos) y otras formas generadas durante la fase III (vaso campanuliforme, jarro pato, urna fina decorada y urnas alisadas).

\section{Relaciones entre Patrones Decorativos sitio Loma Los Brujos y otros Asentamientos Diaguita Inka del río Illapel}

Tradicionalmente se ha considerado la zona de Illapel, y el Choapa en general, como un área marginal a la ocupación incaica en el Norte Chico pues el registro arqueológico no guardaba mayor relación con lo conocido para el resto del Norte Semiárido chileno durante el período Tardío, caracterizado por la presencia de abundantes sitios y patrones cerámicos que demostraban la fusión de grupos locales con población incaica tanto en sus diseños decorativos como en las tecnologías de manufactura de la alfarería. En tanto, la particular morfología de esta región determina la existencia de una serie de rutas naturales que se internan por la precordillera andina y que conducen hacia la vertiente oriental de los Andes, siendo este sector el más angosto del territorio nacional. 
Tabla 1. Patrones decorativos de los sitios Diaguita Inka en el valle de Illapel Decorative pattern in Diaguita Inka sites, Illapel valley.

\begin{tabular}{|c|c|c|c|c|c|c|c|}
\hline & $\begin{array}{c}\text { Loma } \\
\text { Los Brujos }\end{array}$ & $\begin{array}{l}\text { Sucesión } \\
\text { Ramírez }\end{array}$ & $\begin{array}{l}\text { Familia } \\
\text { Carvajal }\end{array}$ & Cárcamo 6 & Césped 1 & Césped 3 & Total \\
\hline Zigzag A & $1(0,22 \%)$ & $11(2,44 \%)$ & $4(0,89 \%)$ & $4(0,89 \%)$ & $2(0,44 \%)$ & $8(1,78 \%)$ & $30(6,68 \%)$ \\
\hline Zigzag B1 & & & & $5(1,11 \%)$ & $1(0,22 \%)$ & & $6(1,33 \%)$ \\
\hline Zigzag B2 & & $2(0,44 \%)$ & $6(1,33 \%)$ & & & $4(0,89 \%)$ & $12(2,67 \%)$ \\
\hline Zigzag C & $3(0,66 \%)$ & $8(1,78 \%)$ & $11(2,44 \%)$ & $7(1,55 \%)$ & $7(1,55 \%)$ & $7(1,55 \%)$ & $43(9,57 \%)$ \\
\hline Zigzag D & & $1(0,22 \%)$ & & & & $1(0,22 \%)$ & $2(0,44 \%)$ \\
\hline Zigzag F1 & & & & & & $1(0,22 \%)$ & $1(0,22 \%)$ \\
\hline Zigzag F2 & & & & & & $1(0,22 \%)$ & $1(0,22 \%)$ \\
\hline Zigzag G & & & & & & $1(0,22 \%)$ & $1(0,22 \%)$ \\
\hline Zigzag $\mathrm{H}$ & & & & & & $1(0,22 \%)$ & $1(0,22 \%)$ \\
\hline Zigzag I & & & & & $1(0,22 \%)$ & & $1(0,22 \%)$ \\
\hline Zigzag J & & & & & & $1(0,22 \%)$ & $1(0,22 \%)$ \\
\hline Zigzag K & & & & & & $1(0,22 \%)$ & $1(0,22 \%)$ \\
\hline Zigzag L & & & & & $2(0,44 \%)$ & & $2(0,44 \%)$ \\
\hline D.Zigzag A & & $2(0,44 \%)$ & $1(0,22 \%)$ & $4(0,89 \%)$ & $2(0,44 \%)$ & $2(0,44 \%)$ & $11(2,44 \%)$ \\
\hline D.Zigzag C & & & & $1(0,22 \%)$ & $1(0,22 \%)$ & & $2(0,44 \%)$ \\
\hline D.Zigzag E & & & $1(0,22 \%)$ & & $1(0,22 \%)$ & $1(0,22 \%)$ & $3(0,66 \%)$ \\
\hline Laberinto B & & & & $1(0,22 \%)$ & & & $1(0,22 \%)$ \\
\hline Ondas A & & $3(0,66 \%)$ & $10(2,22 \%)$ & $1(0,22 \%)$ & & $1(0,22 \%)$ & $15(3,34 \%)$ \\
\hline Ondas C & & & & & & $1(0,22 \%)$ & $1(0,22 \%)$ \\
\hline Ondas D & & $1(0,22 \%)$ & & & $1(0,22 \%)$ & & $2(0,44 \%)$ \\
\hline Ondas F & & $1(0,22 \%)$ & $3(0,66 \%)$ & $6(1,33 \%)$ & $3(0,66 \%)$ & $4(0,89 \%)$ & $17(3,78 \%)$ \\
\hline Cadenas A & & $1(0,22 \%)$ & $2(0,44 \%)$ & $1(0,22 \%)$ & & & $4(0,89 \%)$ \\
\hline Cadenas B & & & $2(0,44 \%)$ & & & $4(0,89 \%)$ & $6(1,33 \%)$ \\
\hline Cadenas C & & $1(0,22 \%)$ & $1(0,22 \%)$ & $1(0,22 \%)$ & & $1(0,22 \%)$ & $4(0,89 \%)$ \\
\hline Cadenas D & & & & & $1(0,22 \%)$ & & $1(0,22 \%)$ \\
\hline Cadenas E & $3(0,66 \%)$ & & $1(0,22 \%)$ & & & & $4(0,89 \%)$ \\
\hline Escalerado & & & $1(0,22 \%)$ & & $1(0,22 \%)$ & & $2(0,44 \%)$ \\
\hline \multicolumn{8}{|l|}{ Reflexión Horizontal } \\
\hline Cuarto Estilo & $3(0,66 \%)$ & $9(2 \%)$ & $9(2 \%)$ & $24(5,34 \%)$ & $7(1,55 \%)$ & $99(22,04 \%)$ & $150(33,40 \%)$ \\
\hline Escalerado & $1(0,22 \%)$ & & & & & & $1(0,22 \%)$ \\
\hline \multicolumn{8}{|l|}{ Reflexión Vertical } \\
\hline Reticulado Oblicuo & $63(14,03 \%)$ & & & & $2(0,44 \%)$ & & $65(14,47 \%)$ \\
\hline Ajedrezado & $4(0,89 \%)$ & $1(0,22 \%)$ & & & & & $5(1,11 \%)$ \\
\hline Cuatripartito B & & $1(0,22 \%)$ & & & & & $1(0,22 \%)$ \\
\hline Hilera Rombos & $16(3,56 \%)$ & & & $3(0,66 \%)$ & & & $19(4,23 \%)$ \\
\hline Traslación & $7(1,55 \%)$ & & & & & & $7(1,55 \%)$ \\
\hline \multicolumn{8}{|l|}{ Clepsidras } \\
\hline Doble línea & $1(0,22 \%)$ & & & & & & $1(0,22 \%)$ \\
\hline Zigzag Cuzqueño & $1(0,22 \%)$ & & & & & & $1(0,22 \%)$ \\
\hline Banda Vertical & $2(0,44 \%)$ & & & & & & $2(0,44 \%)$ \\
\hline Rombo & $2(0,44 \%)$ & & & & & & $2(0,44 \%)$ \\
\hline Reticulado Perpendic. & $1(0,22 \%)$ & & & & & & $1(0,22 \%)$ \\
\hline Traslación Triángulo & $2(0,44 \%)$ & & & & & & $2(0,44 \%)$ \\
\hline Helechos & $6(1,33 \%)$ & & & & & & $6(1,33 \%)$ \\
\hline Traslación & $1(0,22 \%)$ & & & & & & $1(0,22 \%)$ \\
\hline \multicolumn{8}{|l|}{ Bastones } \\
\hline Círculo concéntrico & $1(0,22 \%)$ & & & & & & $1(0,22 \%)$ \\
\hline Paralelas & $1(0,22 \%)$ & & & & & & $1(0,22 \%)$ \\
\hline \multicolumn{8}{|l|}{ Verticales } \\
\hline Zigzag horizontal & $1(0,22 \%)$ & & & & & & $1(0,22 \%)$ \\
\hline Total & $117(26,05 \%)$ & $46(10,24 \%)$ & $50(11,13 \%)$ & $60(13,36 \%)$ & $35(7,79)$ & $141(31,4 \%)$ & 449 \\
\hline
\end{tabular}



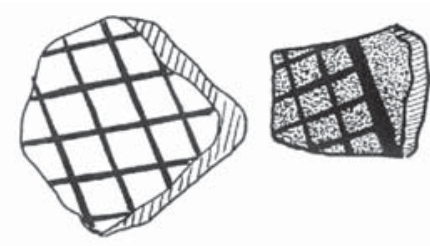

(a)

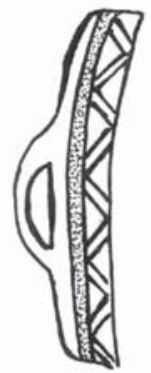

(e)

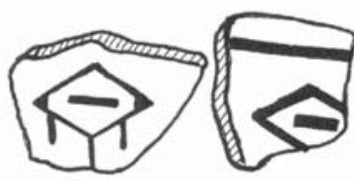

(h)
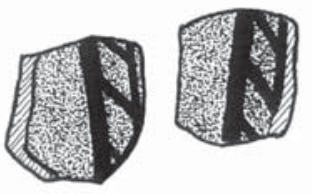

(f)

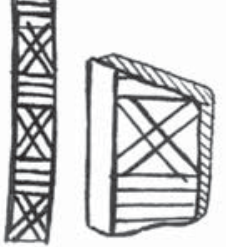

(c)

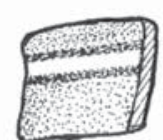

(d)

(b)
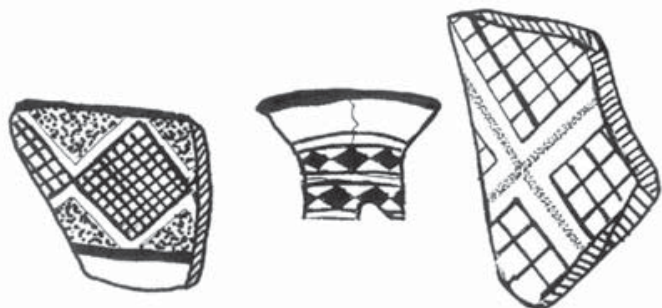

$(\mathrm{g})$

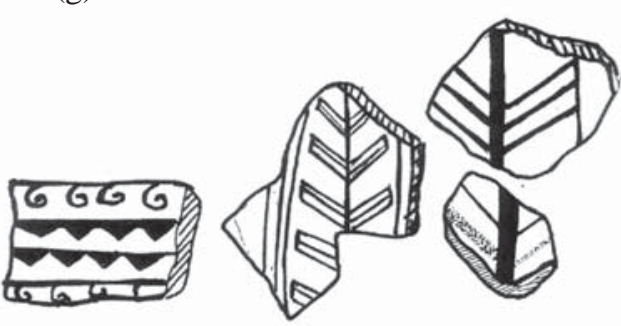

(j)

(k)

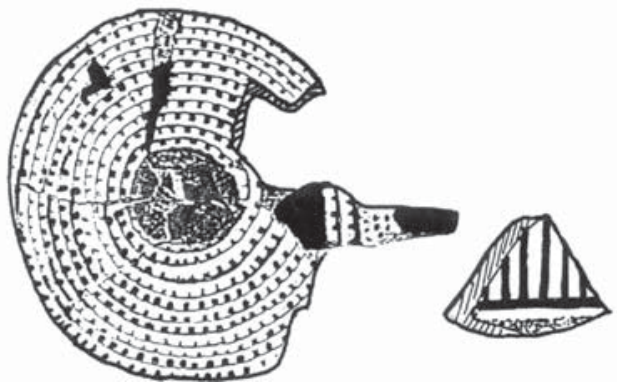

(m)

(n)

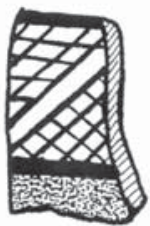

$(\tilde{\mathrm{n}})$

Figura 1. Patrones decorativos sitio Loma Los Brujos. Diseños de origen cuzqueño: (a) Patrón reticulado oblicuo, (b) Patrón ajedrezado, (c) Patrón clepsidras en translación vertical, (d) Líneas paralelas horizontales bajo el borde, (e) Zigzag cuzqueño, (f) Banda con líneas negras paralelas oblicuas, (g) Rombos en hilera, (h) Rombos aislados, (i) Reticulado perpendicular, (j) Triángulos negros invertidos en translación horizontal, (k) "Helechos", (1) Bastones en translación horizontal, (m) Círculos concéntricos con apéndices verticales, (n) Rectas verticales paralelas en translación horizontal, (ñ) Línea zigzag horizontal sobre banda reticulada oblicua.

Decorative patterns, Loma Los Brujos site. Designs of Cuzco origin: (a) Slanting reticular pattern, (b) Checkered pattern, (c) Clepsydra in vertical translation, d) Horizontal parallel lines under the rim, (e) Striping with slating parallel black lines, $f$ ) Rhomboids in row, (g) Isolated rhomboids, h) Perpendicular reticular pattern, (i) Upside down triangles in horizontal translation, ( $j)$ "Ferns", (k) Staffs in horizontal translation, (l) Concentric circle with vertical appendages, $(m)$ Parallel vertical straight lines in horizontal translation,

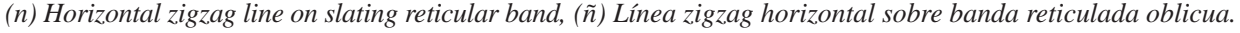




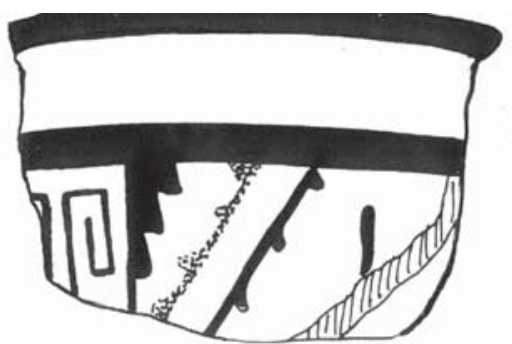

(a)
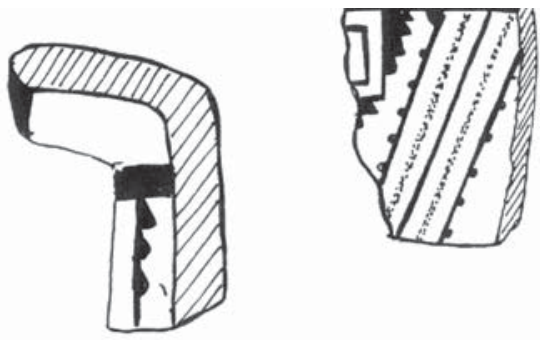

(a)

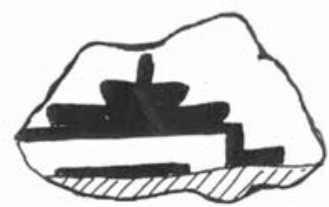

(b)

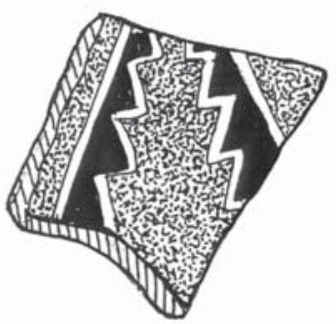

(c)

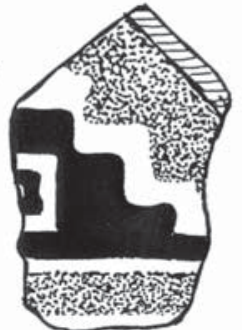

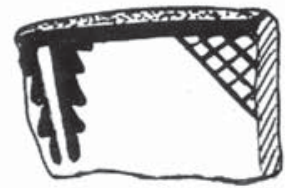

(d)

Figura 2. Patrones decorativos sitio Loma Los Brujos. Diseños de origen Diaguita y mixto Inka Diaguita. (a) Patrón zigzag C, (b) Patrón zigzag A, (c) Patrón cuarto estilo, (d) Diseño mixto: Escalerados en reflexión vertical.

Decorative patterns, Loma Los Brujos site. Design of Diaguita origen and mixed Inka Diaguita designs. (a) Zigzag C pattern, (b) Zigzag A pattern, (c) $4^{\text {th }}$ style pattern, (d) Mixed design: Stepped in vertical reflection.

No obstante, el estudio del arte visual Diaguita en el valle del Choapa (González 2004, 2001), específicamente del río Illapel, dejó en evidencia la existencia de un gran cambio estilístico en la fase Diaguita Inka, en la cuenca superior e inferior de este río, en comparación a lo observado en sitios Diaguita preincaicos de toda la cuenca. Esto se manifiesta en los siguientes antecedentes:

- En los sitios Diaguita incaicos se percibe un gran aumento en el número de patrones decorativos manejados por esta población, algunos de ellos exclusivos de esta fase, propios de la iconografía Diaguita, así como una mejora tecnológica en su manufactura (adelgazamiento de paredes y mejor calidad de los esmaltes y colores).

- Existe un marcado parentesco estilístico entre los sitios incaicos de la cuenca superior, es decir, Césped 3 y Césped 1 (ver Troncoso et al. 2004), y los asentamientos incaicos de la cuenca baja del río (sitios Cárcamo 6, Familia Carvajal y Sucesión Ramírez), en ambos sectores los diseños de origen cuzqueño se encuentran prácticamente ausentes, salvo escasos frag- 


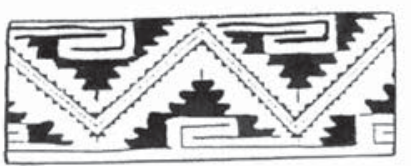

(a)

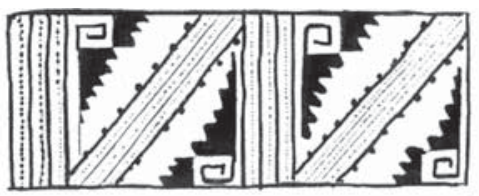

(b)

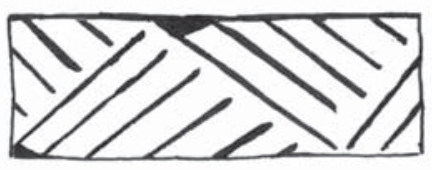

(c)

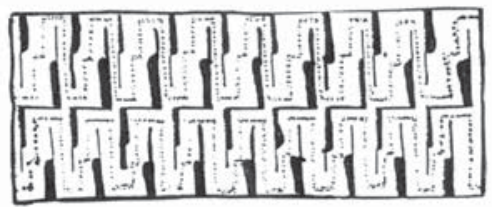

(d)

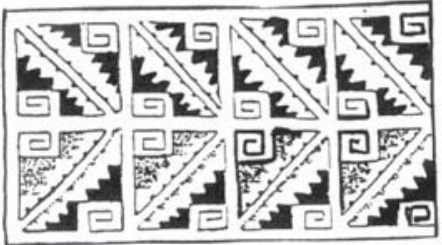

(e)
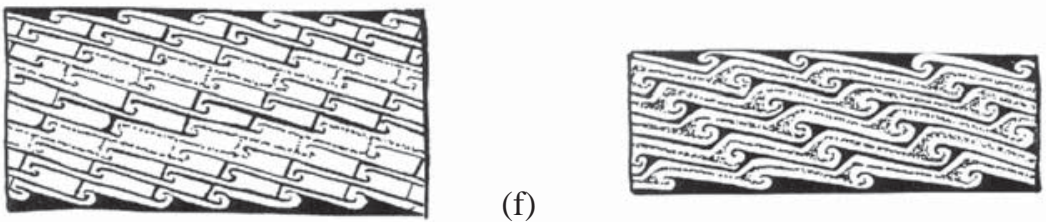

(g)

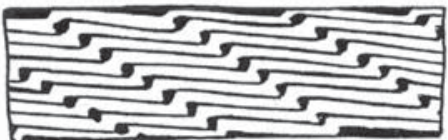

(h)

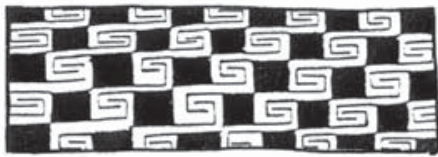

(f)
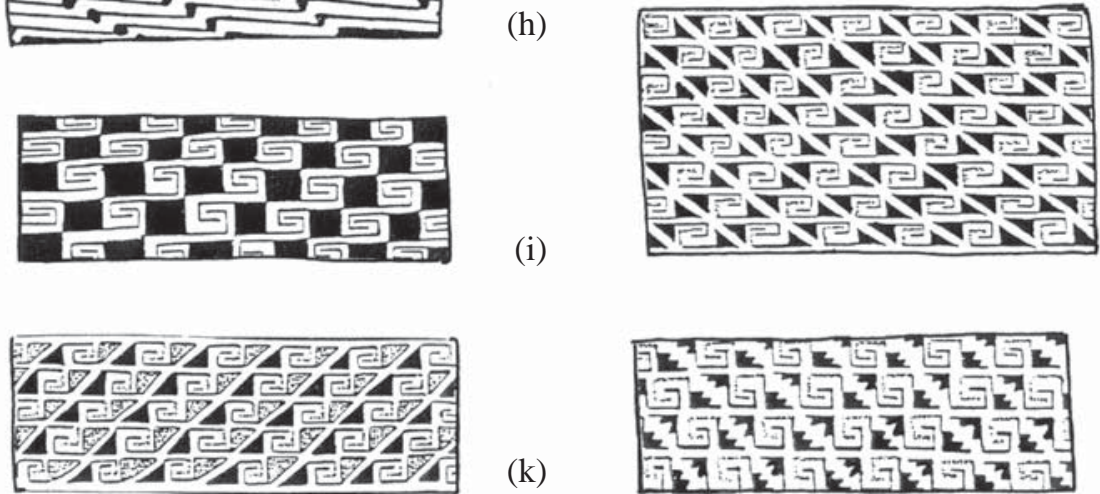

Figura 3. Patrones decorativos del Sitio Familia Carvajal: (a) Patrón zigzag A, (b) Patrón zigzag C, (c) Patrón zigzag B2, (d) Patrón doble zigzag A1, (e) Patrón doble zigzag E1, (f) Patrón ondas A1, (g) Patrón ondas A4, (h) Patrón ondas F1, (i) Patrón cadenas A1, (j) Patrón cadenas B1, (k) Patrón cadenas B2, (l) Patrón cadenas C.

Decorative patterns, Familia Carvajal site: (a) Zigzag A pattern, (b) Zigzag C pattern, (c) Zigzag B2 pattern, (d) Double zigzag A1 pattern, (e) Double zigzag E1 pattern, $(f)$ Wave pattern A1, $(g)$ Wave pattern A4, $(h)$ Wave pattern $F 1,(i)$ Chain pattern A1, $(j)$ Chain pattern B1, (k) Chain pattern B2,(l) Chain pattern $C$. 


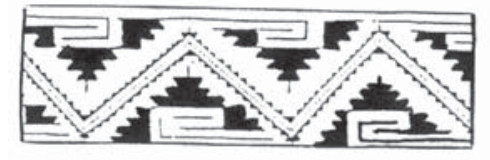

(a)

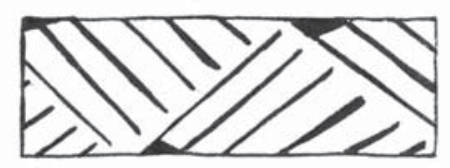

(b)

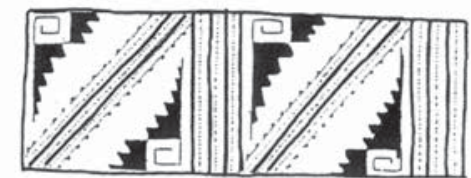

(c)

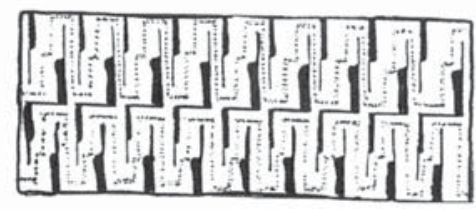

(e)
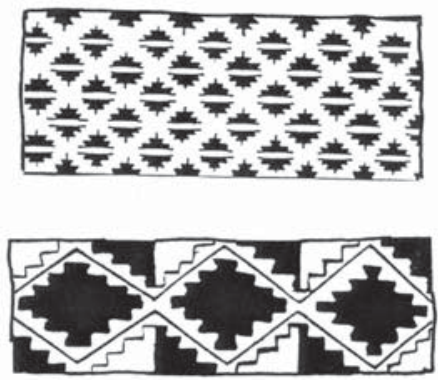

(g)

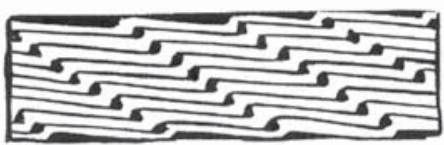

(j)

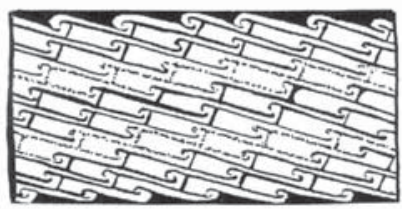

(h)

(i)

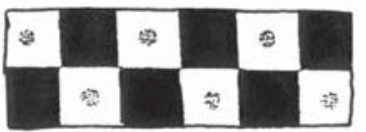

(f)

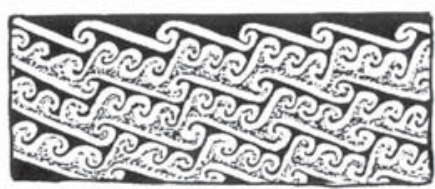

(k)

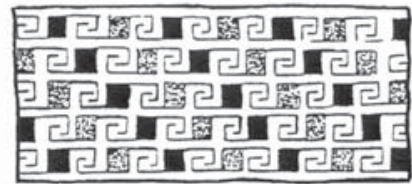

(1)

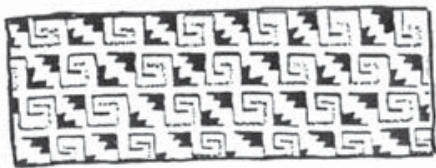

(m)

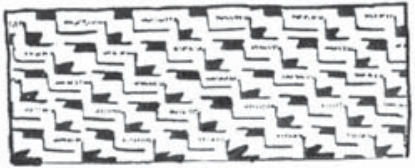

(n)

Figura 4. Patrones decorativos del sitio Sucesión Ramírez: (a) Patrón zigzag A, (b) Patrón zigzag B2, (c) Patrón zigzag C, (d) Patrón zigzag D, (e) Patrón doble zigzag A1, (f) Patrón ajedrezado, (g) Patrón escalerados en reflexión horizontal, (h) Patrón ondas A1, (i) Patrón cuatripartito B, (j) Patrón ondas F1, (k) Patrón ondas D, (1) Patrón cadenas A2, (m) Patrón cadenas C, (n) Patrón cadenas E.

Decorative patterns, Sucesión Ramírez site: (a) Zigzag A pattern, (b) Zigzag B2 pattern, (c) Zigzag C pattern, (d) Zigzag D pattern, (e) Double zigzag Al pattern, ( $f$ ) Checkered pattern, $(g)$ Stepped pattern in horizontal reflection, $(h)$ Wave pattern Al, (i) Quadripartite B pattern, (j) Wave pattern F1, ( $k$ ) Wave pattern D, (l) Chain pattern A2, ( $m$ ) Chain pattern C, ( $n$ ) Chain pattern E. 


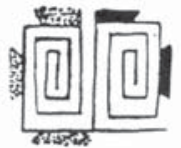

(a)

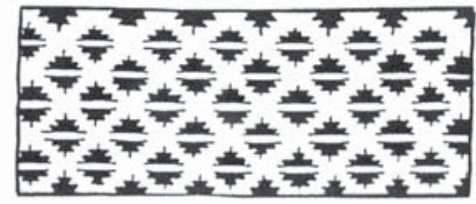

(b)

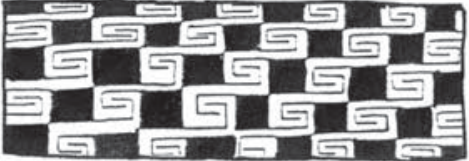

(c)

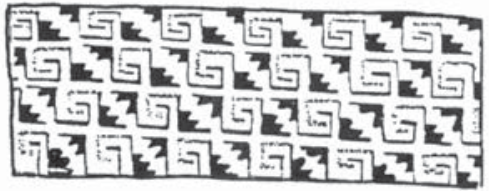

(d)

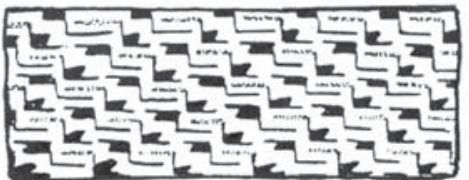

(e)

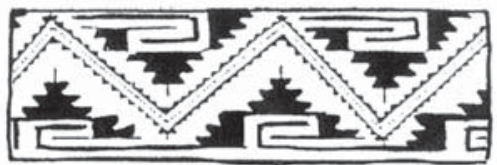

(f)
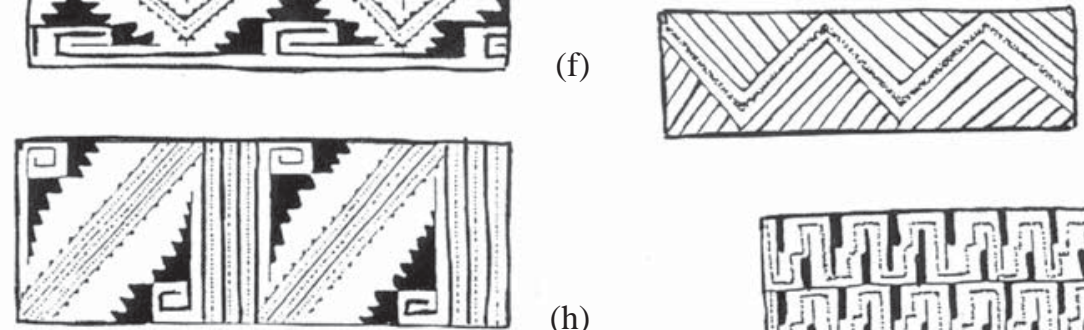

(h)
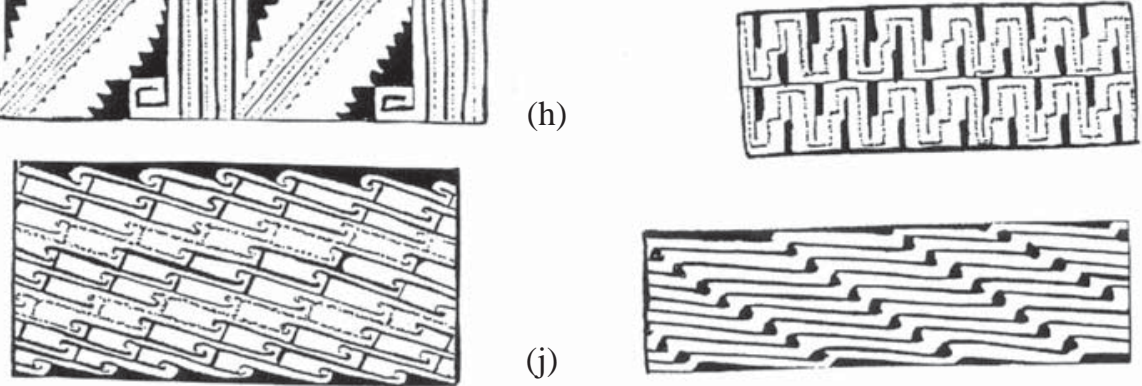

(j)
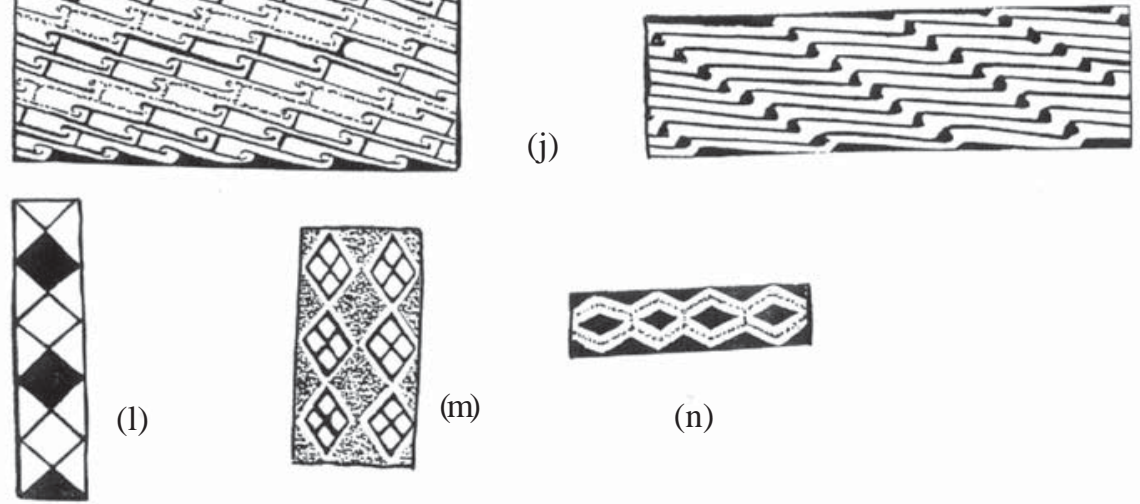

(m)

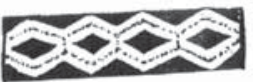

(n)

Figura 5. Patrones decorativos del sitio Cárcamo 6: (a) Laberinto B, (b) Escalerados en reflexión horizontal, (c) Cadenas A1, (d) Cadenas C, (e) Cadenas E, (f) Zigzag A, (g) Zigzag B1, (h) Zigzag C, (i) Doble zigzag A2, (j) Ondas A1, (k) Ondas F1, (1) Rombos en Hilera A, (m) Rombos en hilera B, (n) Rombos en hilera C.

Decorative patterns, Cárcamo 6 site: (a) Labyrinth B, (b) Stepped in horizontal reflection, (c) Chain A1, (d) Chain C, (e) Chain E, (f) Zigzag A, (g) Zigzag B1, (h) Zigzag C, (i) Zigzag A2, (j) Wave A1, (k) Wave F1, (l) Rhomboids in row A, ( $m$ ) Rhomboids in row $B$, (n) Rhomboids in row $C$. 


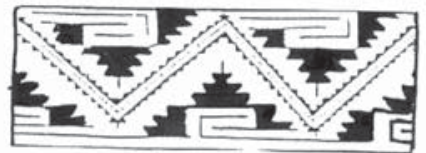

(a)
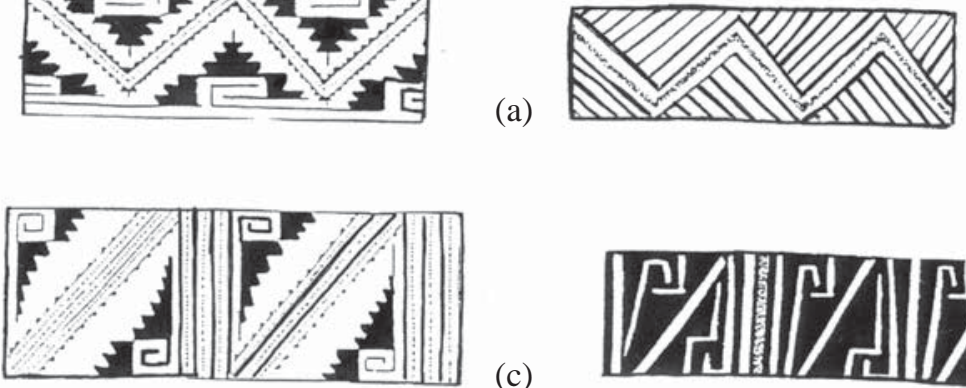

(c)
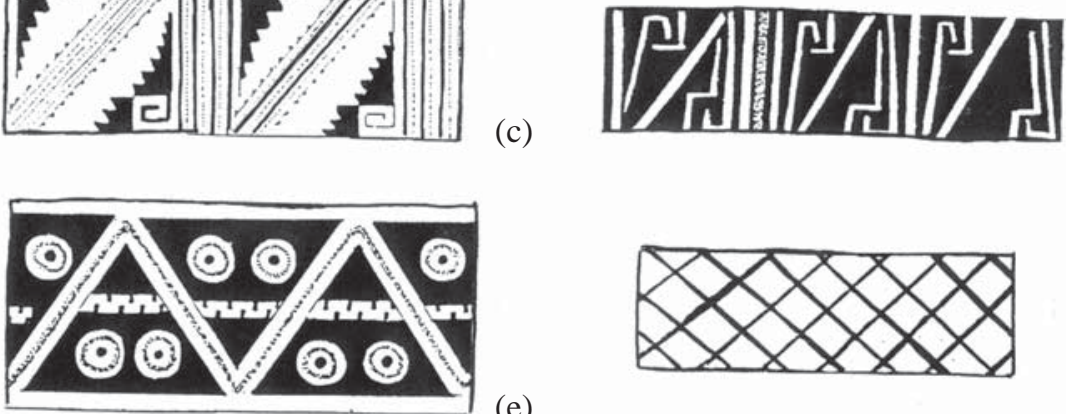

(e)
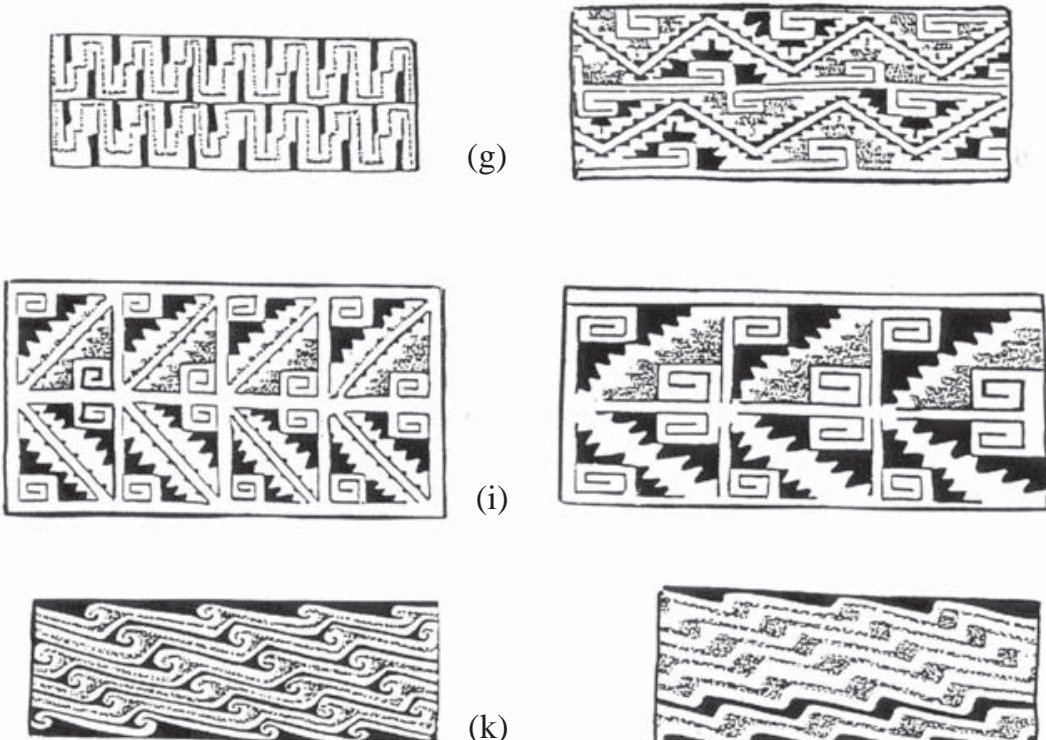

$(\mathrm{k})$
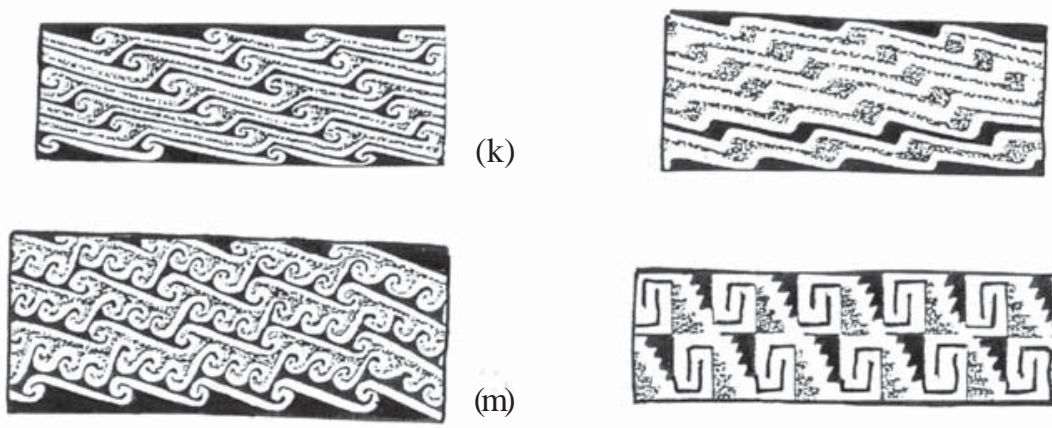

(m)

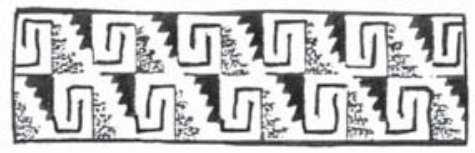

(n)

Figura 6. Patrones decorativos del sitio Césped 1: (a) Patrón zigzag A, (b) Patrón zigzag B1, (c) Patrón zigzag C, (d) Patrón zigzag I, (e) Patrón zigzag L, (f) Reticulado oblicuo, (g) Patrón doble zigzag A2, (h) Patrón doble zigzag C, (i) Patrón doble zigzag E1, (j) Patrón doble zigzag E2, (k) Patrón ondas A4, (1) Patrón Ondas F2, (m) Patrón ondas D, (n) Patrón cadenas D.

Decorative patterns, Césped 1 site: (a) Zigzag A pattern, (b) Zigzag B1 pattern, (c) Zigzag C pattern, (d) Zigzag I pattern, (e) Zigzag L pattern, $(f)$ Slanting reticular, $(g)$ Double zigzag A2 pattern, $(h)$ Double zigzag C pattern, (i) Double Zigzag E1 pattern, (j) Double zigzag E2 pattern, ( $k$ ) Wave A4 pattern, (l) Wave F2 pattern, ( $m$ ) Wave D pattern, ( $n$ ) Chain D pattern. 


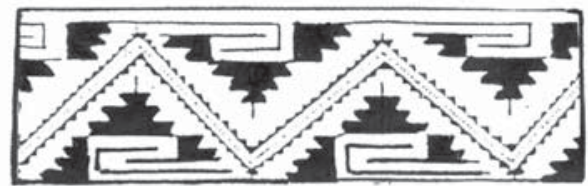

(a)

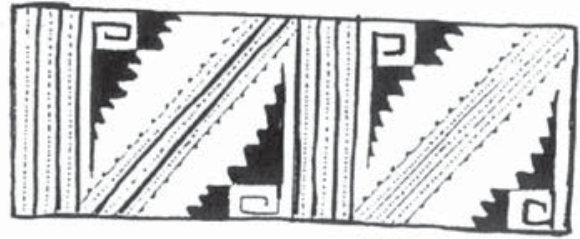

(c)

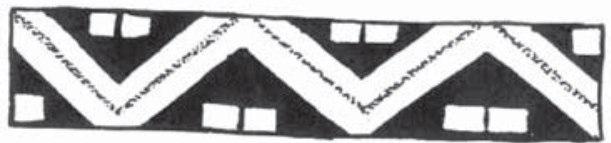

(e)

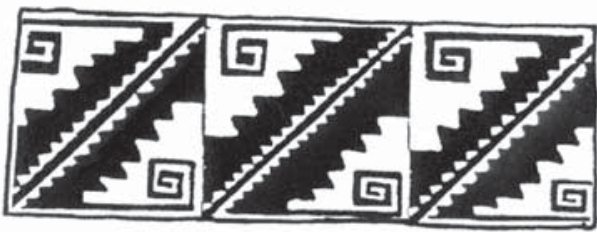

$(\mathrm{g})$

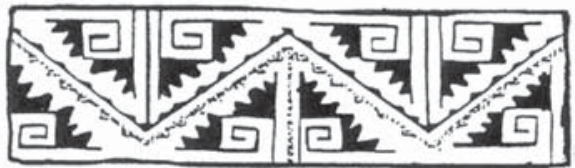

(i)

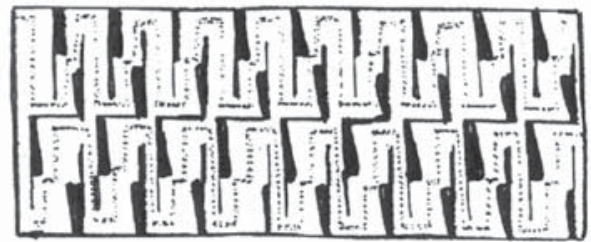

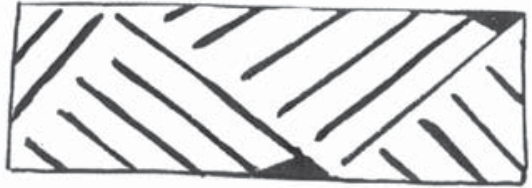

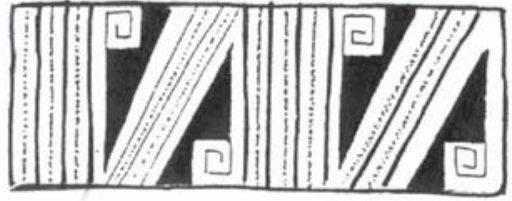

(d)
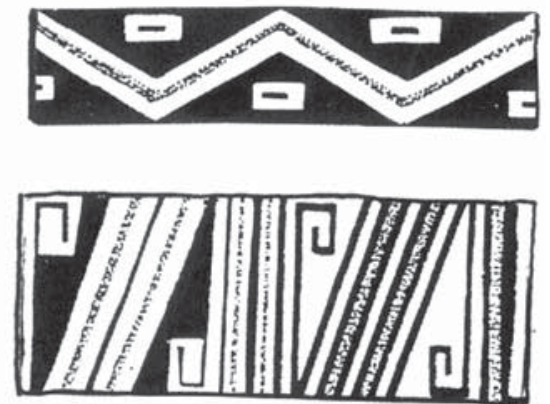

(h)

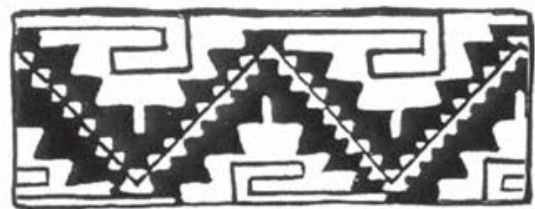

(j)

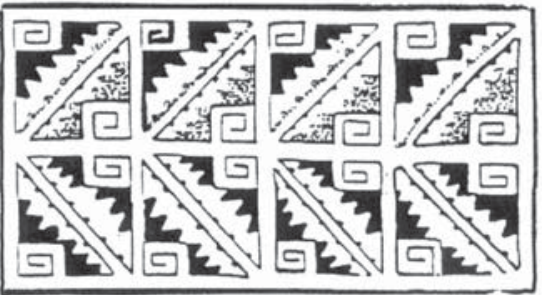

(1)

Figura 7. Patrones decorativos Sitio Césped 3: (a) Patrón zigzag A, (b) Patrón zigzag B2, (c) Patrón zigzag C, (d) Patrón zigzag D, (e) Patrón zigzag F1, (f) Patrón zigzag F2, (g) Patrón zigzag G, (h) Patrón zigzag H, (i) Patrón zigzag J, (j) Patrón zigzag K, (k) Patrón doble zigzag A1, (1) Patrón doble zigzag E1.

Decorative patterns, Césped 3 site: (a) Zigzag A pattern, (b) Zigzag B2 pattern, (c) Zigzag C pattern, (d) Zigzag D pattern, (e) Zigzag F1 pattern, (f) Zigzag F2 pattern, (g) Zigzag G pattern, (h) Zigzag H pattern, (i) Zigzag J pattern, (j) Zigzag K pattern, (k) Double zigzag A1 pattern, (l) Double Zigzag E1 pattern. 


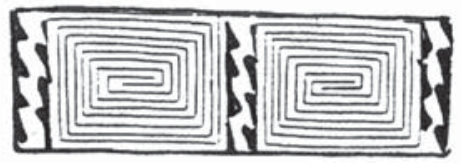

(a)

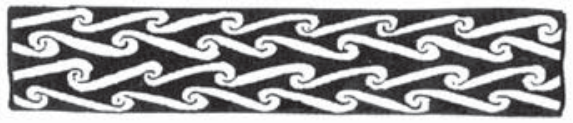

(c)

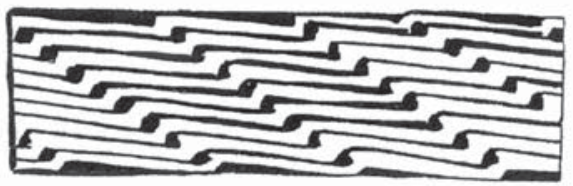

(d)

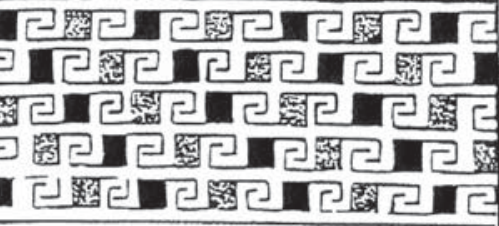

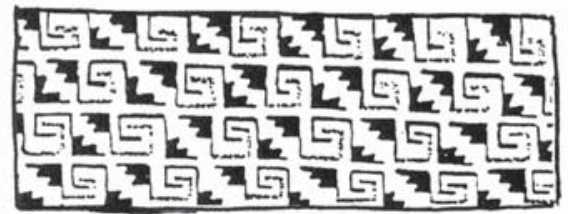

(e)

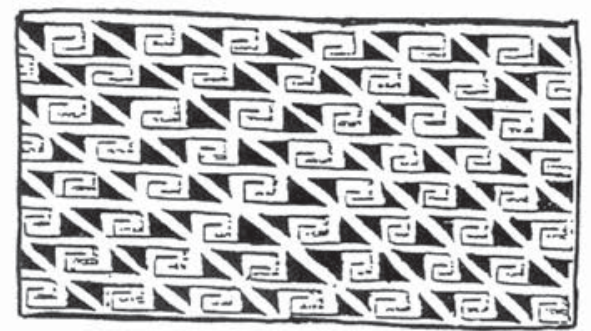

(f)

(g)

(b)

)

Figura 8. Patrones decorativos del Sitio Césped 3: (a) Patrón Laberinto A, (b) Patrón Ondas A 1, (c) Patrón Ondas C 2, (d) Patrón Ondas F1, (e) Patrón Cadenas A 2, (f) Patrón Cadenas B1, (g) Patrón Cadenas C.

Decorative patterns, Césped 3 site: (a) Labyrinth A pattern, (b) Wave A1 pattern, (c) Wave C2 pattern, (d) Wave F1 pattern, (e) Chain A2 pattern, (f) Chain B1 pattern, $(g)$ Chain C pattern.

mentos con el Patrón Rombos en Hilera, Ajedrezado, Reticulado Oblicuo y Patrón Zigzag F1 y F2.

- Otro punto interesante, es la especialización percibida, a nivel espacial, en la ejecución de un determinado patrón simétrico de origen Diaguita (Cadenas), el cual se observó restringido a un área acotada del curso inferior, desarrollándose un gran número de variantes de este patrón, lo que señala un interesante esfuerzo cultural orientado a la exploración de las posibilidades del diseño abstracto y cierta "apropiación espacial" de estructuras simétricas específicas.

En definitiva, observamos un gran parentesco estilístico entre los sitios Diaguita Inka, singularizándose de los de las fases preincaicas, por su riqueza y complejidad, aunque no necesariamente incluyen diseños cuzqueños (Tabla 1). 


\section{Caracterización del Arte Visual Diaguita en el Valle del río Illapel durante la fase Diaguita Inka}

De acuerdo a lo expresado, vemos que, durante la fase Diaguita Inka, en los sitios habitacionales de Césped 7 (Ver Figura 1), Césped 1 (Ver Figura 6), Cárcamo 6 (Ver Figura 5), Familia Carvajal (Ver Figura 3) y Sucesión Ramírez (Ver Figura 4), se observa un grupo de patrones decorativos, mayoritariamente de origen Diaguita, que se trasladan en conjunto y que ligan estrechamente los desarrollos culturales del sector La Colonia-Cárcamo en el curso inferior y el sector de Césped en el curso superior del río Illapel. Estos antecedentes apoyan la idea que estamos frente a un nuevo momento en la prehistoria del río Illapel, caracterizado por la llegada de nuevas ideas en torno al arte visual, desarrollándose con fuerza un nuevo tipo de diseños, siempre bajo las restricciones estilísticas propias de la cultura Diaguita pero que no habían sido exploradas antes de la llegada de los Inkas al valle. Pensamos que puede reflejar también el arribo de artesanos provenientes del área Diaguita nuclear que difunden este nuevo grupo de diseños Diaguita en el área, muy probablemente bajo el régimen de mitimaes incaicos.

En tanto, en los sitios Diaguita Inka mencionados, la presencia de diseños de origen cuzqueño es mínima, reduciéndose al Patrón Rombos en Hilera (Ver Figura 5 letras 1, m, n), Ajedrezado (Ver Figura 4 letra f), Reticulado Oblicuo (Ver Figura 6 letra f) y Patrón Zigzag F1 y F2 (Ver Figura 7 letras e y f), con una insignificante frecuencia de representación. Algo muy diferente ocurre con los patrones decorativos del sitio Loma Los Brujos donde los patrones de origen cuzqueño alcanzan al 93,16\% de la muestra.

Por otra parte, no debemos olvidar que existe un bagaje representacional que es mantenido desde los tiempos preincaicos y que es muy propio del río Illapel González (2004), tales como los patrones Zigzag A, Zigzag B, Zigzag C, Zigzag D, Zigzag G, Doble Zigzag A 1, Doble Zigzag A 2, Doble Zigzag B, Ondas A1, Ondas A2, Ondas A 4, Ondas B, Ondas E, Reticulado Diaguita A 1, Patrón Laberinto, Patrón Cuatripartito A y Cuarto Estilo, registrados en los sitios Diaguita I y II del Valle. Ellos conforman un conjunto de patrones decorativos de alta representación y que se difunden a lo largo de toda la cuenca del río Illapel.

Ahora bien, la implicancia del sitio Loma Los Brujos en nuestra concepción de los patrones de- corativos del área es considerable, dado que evidencia la existencia de dos realidades completamente distintas de arte visual, que coexisten durante la fase Diaguita Inka, diferencia que tiene, en nuestra opinión, fuertes connotaciones de orden social e ideológico.

En efecto, del total de 117 fragmentos decorados con patrón simétrico reconocible recobrados de este sitio, un 93,16\% es de origen cuzqueño, mientras se registraron sólo 7 fragmentos de origen Diaguita y uno de origen mixto inca/diaguita. En tanto, se establecieron 15 patrones de origen Inka Cuzqueño, destacándose por su frecuencia de representación los patrones reticulado oblicuo $(53,84 \%)$ y rombos en hilera $(13,67 \%)$ del total de fragmentos recobrados. Los diseños de origen Diaguita corresponden al Patrón Zigzag C y Zigzag A, y el Patrón Cuarto Estilo. Los dos primeros presentan una alta representación desde la fase Diaguita II y el último es de origen preincaico pero alcanza una alta frecuencia en la fase Diaguita III.

Finalmente, y considerando todo lo anteriormente expuesto, planteamos, con un grado aceptable de certeza, que los patrones decorativos generados durante la fase Diaguita III incluyen los siguientes:

- Patrones Decorativos Diaguita que ya existían en el valle de Illapel antes de la llegada de los Inkas: Ellos son Patrón Zigzag A, Zigzag B 2, Zigzag C, Zigzag D, Zigzag G, Doble Zigzag A 1, Doble Zigzag A 2, Ondas A 1, Ondas A 4, Ondas F 1, Reticulado y Cuarto Estilo.

- Patrones Decorativos Diaguitas que no existían en el valle de Illapel antes de la llegada de los Inkas y que se encuentran descritos en el área Diaguita nuclear: Patrón Zigzag J, Patrón Zigzag L, Doble Zigzag E 1 y E 2, Patrón Ondas C 2 y D; Cadenas A 2, B 1, B 2, C, D y E.

- Patrones decorativos locales no registrados en el área Diaguita nuclear ni en el área de estudio en tiempos preincaicos: Patrón Zigzag H, I, K, Patrón Cuatripartito B, Patrón Laberinto B.

- Patrones Decorativos Inka-Cuzqueños: Ajedrezado; Rombos en Hilera A, B y C; Zigzag F1 y F2; Reticulado Oblicuo; Clepsidras en translación vertical separadas por líneas horizontales paralelas; Línea Negra paralela horizontal bajo el borde; Zigzag Cuzqueño; Banda Vertical Negra sobre café con líneas negras paralelas oblicuas en su interior; Rombos Aislados; Reticulado Perpendicular; Triángulos negros 
invertidos en translación horizontal; "Helechos"; Bastones en translación horizontal ("embrión de la quínoa"); Círculos concéntricos con apéndices verticales; Banda con rectas verticales paralelas en transación horizontal; y Línea zigzag horizontal sobre banda reticulada oblicua.

\section{Conclusiones Preliminares}

El estudio del arte visual Diaguita en un área acotada (río Illapel) ha resultado ser una gran ventana, a través de la cual observamos una serie de procesos sociales que contribuyen a nuestra comprensión de la cultura Diaguita e Inka en su totalidad. Desde una perspectiva diacrónica y sincrónica hemos presenciado la evolución de este arte a través del tiempo y la singular fisonomía que adopta en esta región el período de influencia incaica. No debemos olvidar que nos encontramos en la frontera meridional del territorio Diaguita y resultaba hasta cierto punto esperable un cambio respecto del área Diaguita nuclear. No obstante, ignorábamos la naturaleza de esta diferenciación. Pues bien, el estudio de los patrones decorativos Diaguita durante el período de influencia incaica ha evidenciado un notorio enriquecimiento del bagaje estilístico manejado con anterioridad. Los sitios diaguita incaicos utilizan más de una docena de diseños diferentes, mientras que en los sitios preincaicos este número no supera los cinco patrones diferentes. Por otra parte, los sitios de influencia incaica, a excepción del asentamiento de Loma Los Brujos, manifiestan un gran parentesco estilístico, compartiendo un elevado número de diseños. Desde el punto de vista tecnológico también se detectan mejorías técnicas tales como el adelgazamiento de las paredes y una mejor calidad de los esmaltes.

En tanto, el análisis iconográfico aporta interesantes elementos que contribuyen a caracterizar este período en el Valle del Choapa. Por una parte, advertimos una continuidad en la representación de diseños Diaguita preincaicos, al tiempo que se registran nuevos diseños Diaguita que no habían sido detectados en estas latitudes con anterioridad, reflejando probablemente el arribo de artesanos Diaguita de las áreas nucleares (ríos Elqui y Limarí), bajo el régimen de mitimaes. A este respecto, es de interés mencionar lo expresado por Parsinnen (2003) en relación a las distintas clases de mi- timaes existentes en el imperio Incaico, así como su diversa relación con la organización política del Incanato. En efecto, el autor mencionado distingue entre mitimaes con énfasis en funciones económicas, mitimaes militares, mitimaes con énfasis en funciones sociopolíticas y, finalmente, mitimaes con énfasis en funciones religiosas. Acerca de la primera clase de mitimaes mencionada el autor señala lo siguiente:

En algún punto indeterminado de la historia, los Inkas comenzaron a establecer en las provincias verdaderos pueblos de artesanos y trabajadores especializados con el fin de emplearlos en el transporte, almacenamiento o manufactura de objetos de metal, sandalias, ropa, entre otros, que las festividades, curacas, soldados y trabajadores mitt'ayocs necesitaban (Pärssinen 2003:151).

Agrega al respecto que:

sabemos que los ceramistas olleros mitima de Cajamarca trabajaban a tiempo completo y definitivamente fueron yanas (Pärssinen 2003:151).

Resulta muy interesante asociar estos planteamientos con lo visto en los sitios Diaguita III del valle de Illapel, exceptuando Loma Los Brujos. Estimamos que los ceramistas Diaguitas del valle del Illapel claramente pertenecieron a la clase de mitimaes "con énfasis en funciones económicas", quienes se desempeñaban como trabajadores especializados, a tiempo completo, y no participaban de la organización política del valle.

La existencia en el valle de ceramistas diaguita del área nuclear bajo el sistema de mitimaes debe también ser asociada con la existencia de una ruta natural hacia los territorios trasandinos y al principio rector de reciprocidad que regía la relación entre la organización política Inka y los nuevos pueblos conquistados. Según el autor citado resulta esencial para la administración inca

confirmar y reconfirmar esos lazos a través de muchas y variadas maneras. Una de estas maneras tradicionales consistía en entregar "dones recíprocos" a los jefes étnicos, con el fin de ganar su obediencia y 
obtener del pueblo sometido la mano de obra que el Estado necesitaba para sus propósitos (Pärssinen 2003:141).

Nos parece que es razonable plantear, a partir de la evidencia material, la existencia de un traslado de mitimaes diaguitas del área nuclear, especializados en la manufactura cerámica, hacia el río Illapel, ruta natural hacia Argentina. Estos artesanos a tiempo completo contaban con un bagaje representacional de origen Diaguita mucho más completo que el existente en el valle, con anterioridad a la llegada de los Inkas. Lo mismo puede decirse en cuanto a la tecnología de manufactura, la cual les permite el desarrollo de vasijas más delgadas y con mejor calidad del color y esmalte. Nos parece que este aumento de la producción cerámica guarda relación con la necesidad del Incanato de contar con bienes suntuarios destinados a reforzar las relaciones de reciprocidad con las poblaciones incorporadas a su Imperio, especialmente en el área meridional (noroeste argentino y zona central de Chile).

Por otra parte, en relación al universo representacional de los sitios Diaguita incaicos destaca la generación de ciertos diseños locales innovadores, que revierten las pautas cromáticas de diseños Diaguita preincaicos de larga data, tales como el Patrón Zigzag A, el cual invierte sus colores de fondo blanco a negro y reemplaza los motivos tradicionalmente negros, por blancos. Pensamos que esta estrategia gráfica refleja en algún grado los profundos cambios sociales que estaba sufriendo la sociedad como un todo; este replanteamiento de normas estilísticas hondamente arraigadas en la cultura Diaguita revela, en cierto modo, el quiebre de un imago mundi que ya no retornaría más. Hemos detectado un juego similar de inversión de colores durante la fase Diaguita Inka en el asentamiento Diaguita Incaico de Huana (Niemeyer 1969), no obstante, este sitio destaca por una mayor variabilidad y complejidad en estos patrones "en negativo". Hacemos referencia a los patrones Doble Zigzag D1, Doble Zigzag A; Reticulado y escalerados en reflexión vertical sobre cuadrados en translación. Todos estos patrones han variado el color de fondo de la banda de diseño de blanco a negro.

También nos parece destacable la especialización espacial detectada en los sitios del sector de La Colonia respecto del patrón decorativo deno- minado Cadenas. Pese a que una variante de ese patrón había sido registrada en tiempos preincaicos (patrón cadenas A 1), durante la fase Diaguita Inka surgen seis variantes de este patrón en una franja de $3 \mathrm{~km}$ a lo largo del río Illapel. ¿Qué puede estarnos señalando dicha especialización? En primer término, revela la existencia de una entidad externa que, de algún modo, condiciona la producción de determinados diseños. Es un cambio evidente respecto de la forma en que estas sociedades campesinas abordaban su producción iconográfica, creo que evidencia algún grado de estrés o presión sobre las opciones estéticas de estas poblaciones.

Ahora bien, destaca también el hecho que en los asentamientos Diaguita incaicos del río Illapel, con exclusión del sitio Loma Los Brujos, los diseños de origen cuzqueño se encuentran virtualmente ausentes, resultando muy difícil inferir su pertenencia a la fase Diaguita III a partir, exclusivamente, del análisis de sus patrones decorativos, los cuales son predominantemente de origen Diaguita preincaico.

Esta situación es completamente diferente a lo observado en el área Diaguita nuclear donde, a modo de ejemplo, de acuerdo a los resultados del análisis de 234 piezas de la fase Diaguita Inka procedentes del valle de Elqui, con 166 diseños diferentes, vimos que 104 de ellos eran de origen cuzqueño $(62,65 \%$ del total), 36 de origen diaguita $(21,08 \%$ del total) y 10 de origen mixto incadiaguita (6,024\% del total). Algo similar ocurre con la expresión gráfica de referentes simbólicos cuzqueños, específicamente los diseños cuatripartitos. En efecto, ellos alcanzan aproximadamente al $50 \%$ de las piezas mencionadas (González 1995). Recordaremos que los principios simbólicos cuatripartitos forman parte de las estructuras subyacentes y ordenadoras de cultura incaica. Su expresión gráfica considera los diseños generados por doble reflexión especular, así como clepsidras, cruces diametrales, señalización de cuatro sectores equidistantes del ceramio y rombos (González 1998).

De igual modo, el estudio de las prácticas mortuorias del sitio Diaguita Inka de Pisco Control, en la ciudad de Ovalle, en el área nuclear, reveló que de 14 sepulturas recobradas, 9 de ellas presentaban en su ajuar piezas dobles o con diseños cuatripartitos. ¿Cómo explicar entonces esta falta de interés en el Valle de Illapel por reiterar 
principios simbólicos e iconográficos tan sobrevalorados por la cultura Inka? ¿A quién estaban dirigidos estos mensajes simbólicos? Al parecer, esta suerte de periferia en que se encuentran las poblaciones Diaguita del río Illapel determina también el empleo de una estrategia incaica de interacción diferente a la establecida en las áreas Diaguita nucleares. No obstante, nos encontramos con una ocupación efectiva del territorio por parte de los contingentes incaicos y es evidente el énfasis en la explotación de recursos y la reutilización de antiguas rutas hacia el territorio trasandino.

Para entender los registros aportados por el sitio Loma Los Brujos es importante meditar sobre lo planteado por Pärssinen (2003) en torno a que la expansión Inka fue rápida y superficial, basada en lazos personales de "adhesión" y alianza entre el Inka y los jefes provinciales. El autor señala en relación al tamaño de las provincias incas que no ha encontrado pruebas que sustenten la teoría de Ake Wedin (1965), según la cual el área de una provincia típica inca estaba determinada sobre la base de un territorio natural, como podría serlo un valle, o sobre la base de una tribu que habitaba una cierta área y hablaba un mismo idioma. Esto no quiere decir, a juicio de Pärsissnen, que los diferentes grupos étnicos o los "territorios naturales", etc., no hayan influido en la formación de las provincias incas, sino que el sistema inca no era tan simple como para que cada valle o tribu formara una provincia. Concluye al respecto que:

Todo esto podría significar que el tamaño de una provincia normal era un compromiso de varios factores, como las fronteras naturales (valles, etc.), el número de tribus y lenguas, la distancia entre otras provincias, la ubicación de las capitales preincaicas, la calidad de la anterior organización política y el tamaño de la población (Pärssinen 2003:260).

Enfatiza el autor a este respecto que las provincias incas "-más que territorios fijos- eran “personas” (Pärssinen 2003:262), y es por ello que Pizarro repartió curacas -y no territorios- a los primeros encomenderos. Por otra parte, Pärssinen también destaca el hecho que "el Estado Inka era una sociedad clasista y altamente jerarquizada, donde las diferencias entre clase alta y clase baja eran muy acentuadas"; citando a Karsten (1946) agrega que "Nada fue más ajeno a la mentalidad inca que la idea de la igualdad entre los seres humanos" (Pärssinen 2000:157).

Estas reflexiones aportan mucho en la comprensión de las estrategias de interacción diferencial que apreciamos entre los Inkas y los diaguitas del área Diaguita nuclear, en oposición a lo observado en el área Diaguita meridional. Nos parece que estos lazos personales de adhesión entre los curacas Diaguita y los Inkas únicamente operaron en el área nuclear, manifestándose en una gran compenetración a nivel de cultura material y referentes simbólicos propiamente incaicos.

En mi opinión, la oposición percibida entre el sitio Loma Los Brujos y los restantes asentamientos Diaguita Inka del valle es una manifestación de esta aludida desigualdad radical entre lo inca y lo no inca. Loma Los Brujos es el único asentamiento Diaguita con estructuras de piedra registrado en el valle, se localiza en un sector predominante del curso medio del río Illapel, que lo hace visible a gran distancia, y desde donde también puede acceder visualmente a los asentamientos Diaguita Inka del curso inferior. En tanto, su arte visual es autorreferente y reconcentrado en la iconografía cuzqueña, donde el 93,16\% de los patrones decorativos cerámicos es de origen inca, evidenciando de este modo una frontera invisible que lo distancia de los restantes asentamientos de la fase III.

Recién planteamos que operó en este valle el sistema de mitimaes, explicando de este modo el arribo de tantos patrones decorativos Diaguita nunca antes registrados, pero el arte Diaguita jugó un rol muy diverso al percibido en el arte visual de las áreas nucleares, donde logró penetrar, transformar y redefinir muchas estructuras de diseño cuzqueño, cargadas de significado simbólico, como es el caso de la "doble reflexión especular" (González 1998). No obstante, en Illapel, la desigualdad es retomada y reiterada visual y espacialmente, bajo un canon que separa a los unos de los otros. Así nos explicamos la virtual ausencia de diseños cuzqueños en los asentamientos diaguita inca del curso inferior y superior del río, en contraste con la mínima manifestación de diseños diaguita en Loma Los Brujos, que da paso a una iconografía netamente cuzqueña.

A este respecto, es de interés mencionar los resultados que hemos obtenido del análisis de los patrones decorativos de las piezas y fragmentería 
cerámica del sitio Huana, excavado por Niemeyer (1969), pertenecientes a la colección del Museo Nacional de Historia Natural. Este sitio arqueológico se ubica en la comuna de Monte Patria (Valle del Limarí), en los campos de la antigua hacienda de Huana Abajo, al lado sur del río Grande, que actualmente se encuentran inundados por las aguas del Embalse La Paloma. Se trata de la excavación de dos estructuras pircadas rectangulares construidas a una, dos y tres hiladas de piedra, al interior de las cuales se identificó un estrato de ocupación que aportó restos arqueofaunísticos (camélidos, roedores, peces y aves), malacológicos, líticos y cerámicos. Las evidencias cerámicas manifiestan claramente la filiación Diaguita Inka de este sitio, destacando la presencia de fragmentos de platos playos, platos ornitomorfos, vasijas urniformes, aríbalos, vasos campanuliformes altos y normales, keros, jarros pato y escudillas Diaguita III.

La muestra analizada se compone de 95 fragmentos cerámicos con patrón simétrico reconocible, de los cuales un 28,42\% es de origen Diaguita, registrándose 15 diseños diaguita diferentes, agrupados en 7 patrones decorativos. Los diseños de origen mixto alcanzan a 4 diseños. La iconografía cuzqueña, en tanto, se expresa en un 67,36\% de la muestra, registrándose diseños más variados y complejos que en Loma Los Brujos. Es decir, la frontera estilística entre diseños incas y diaguitas en el área diaguita nuclear es mucho más permeable. Existe también un bagaje de diseños Inkas mucho más completo que en el río Illapel.

Esto nos lleva a pensar que en el área de Illapel, los lazos personales de "adhesión" y alianza entre el Inka y los jefes locales revistieron un ca- rácter diverso de los generados en el área diaguita nuclear, mucho más débiles, o tal vez, inexistentes. Los antecedentes examinados nos llevan a pensar que el área de Illapel tiene importancia para el Inka, principalmente como lugar de tránsito hacia el área transcordillerana, situación que explicaría la localización de centros de producción cerámica, bajo el régimen de mitimaes, tanto en el curso medio como superior del río. El asentamiento de Loma Los Brujos, en tanto, pareciera ser un enclave netamente cuzqueño destinado a supervigilar la producción y traslado a sus lugares de destino de este arte visual de fisonomía diaguita. Por otra parte, la baja complejidad de los patrones cuzqueños presentes en Loma Los Brujos, donde un 53,84\% corresponde al patrón reticulado oblicuo, sugiere que se trata de un arte cuzqueño más estandarizado y simple, que el producido en el área Diaguita nuclear. Puede que esta sobresimplificación se deba a que sus destinatarios no forman parte de esta privilegiada esfera configurada por la población Diaguita localizada entre los ríos Elqui y Limarí, cuyos integrantes, por alguna razón que aún no logramos determinar, fueron integrados a una suerte de elite dentro del Imperio.

En definitiva, pensamos que el aporte de la presente investigación radica en que nuestra visión sobre la fase Diaguita Incaica va ganando en matices y perdiendo rigidez; si bien es cierto que Inkas y Diaguitas dieron cuenta de un encuentro cultural fructífero y profundo, esta interrelación no fue homogénea en todo el territorio Diaguita, las estrategias variaron al interior de sus fronteras y estamos recién comenzando a comprender las condicionantes de esta variación.

\section{Referencias Citadas}

Cornejo, L.

1989 El plato zoomorfo diaguita. Su variabilidad y especificidad. Boletín del Museo Chileno de Arte Precolombino 3:47-80

Fernández Baca, J.

1971 Motivos de la Ornamentación de la Cerámica Inca Cuzco. Tomo I y II. Librería Studium Ed. Lima.

González, P.

1995 Diseños Cerámicos Diaguita-Inka: Estructura, Simbolismo, Color y Relaciones Culturales. Tesis para optar al título de arqueóloga, Departamento de Antropología, Universidad de Chile. Santiago.
1998 Doble reflexión especular en los diseños Diaguita Inca: de la imagen al símbolo. Boletín del Museo Chileno de Arte Precolombino 7:39-52.

2001 Estrategias Incas de Interacción Diferencial: Incas y Diaguitas en el Valle de Illapel. Ponencia presentada en XIV Congreso Nacional de Arqueología Argentina, Rosario.

2004 Patrones decorativos y espacio: el arte visual Diaguita y su distribución en la cuenca del río Illapel. Actas del XV Congreso Nacional de Arqueología Chilena. Chungara Revista de Antropología Chilena Volumen Especial: 767781. 
Karsten, R.

1946 Inkavaltio ja sen Kulttuuri. Editorial Tammi. Helsinki.

Niemeyer, H.

1969 El yacimiento arqueológico de Huana. Boletín de Prehistoria de Chile. Departamento de Historia. Universidad de Chile 2-3:2-65.

Pärssinen, $M$.

2003 El Inka y su Organización Política. Traducido al castellano por Ana María Stahl y Pilar Rosselló. IFEA. Instituto Francés de Estudios Andinos. Tomo 153 Colección “Travaux de l'Institute Français d'Études Andines.

Troncoso, A., C. Becker, P. González, D. Pavlovic y J. Rodríguez

2004 Césped 3, asentamiento del período Diaguita Incaico sin cerámica Diaguita fase III en el curso superior del río Illapel, IV Región, Chile. Actas del XV Congreso Nacio- nal de Arqueología Chilena, Arica. Chungara Revista de Antropolgía Chilena Volumen Especial: 893-906.

Washburn, D.

1977 A Symmetry Analysis of Upper Gila Area Ceramic Design. Papers of the Peabody Museum of Archaeology and Ethnology. Vol. 68. Cambridge, Mass.

1983 Toward a theory of structural style in art. En Structure and Cognition in Art. New Direction in Archaeology, editado por D. Washburn, Cambridge University Press, Cambridge.

Washburn, D. y D. Crowe

1988 Symmetries of Culture. Theory and Practice of Plain Pattern Analysis. University of Washington Press, Washington.

Wedin, A.

1965 El Sistema Decimal en el Imperio Incaico: Estudio sobre Estructura Política, División Territorial y Población. Editorial Insula, Madrid. 